in some way towards the causation. Epistaxis in children occurs much less frequently and the severity is less than in an adult; it usually follows an injury to the nose or as part of an upper respiratory infection. I would like to emphasize that unusual causes of epistaxis are extremely rare; I have seen only one or two cases of blood dyscrasia causing epistaxis in 25 years of otolaryngological practice. Hereditary familial telangiectasia does occur, but again is extremely uncommon.

We are therefore left with a middle-aged or elderly person who is brought in by ambulance with his nose pouring blood. Such a person may lose a large volume of blood in a very short time and it would be wrong to regard this lightly because it might upset his cardiovascular system and precipitate a stroke or a coronary thrombosis. Such a patient requires admission to hospital immediately and it is essential to sedate him adequately. Emphasis must be laid on giving the patient complete peace and quiet. It is immaterial if the bed sheets are bloodstained or if his pyjamas look untidy. Peace and quiet is so important that whenever possible he should be nursed in a side-room away from a ward television set and nurses who bustle and gossip. Relatives can also cause a great deal of distress, and the patient is better if they are kept away from him in the early stages. Adequate sedation is essential and morphine 10 or $15 \mathrm{mg}$ every six hours for $\mathbf{4 8}$ hours is required. It should be given regularly, not when the house surgeon or ward sister thinks it is necessary. Local treatment to the nose is helpful but it is impossible to expect to be able to see the bleeding point and cauterize it. The best that can be done is to insert a small pledget cf cotton-wool soaked in $10 \%$ cocaine with adrenaline. This will anaesthetize the nose, reduce the swelling of the mucosa, and also reduce the bleeding. A pack of half-inch $(12-\mathrm{mm})$ Vaseline ribbon gauze about a yard $(0.9 \mathrm{~m})$ long is inserted starting from the floor and going upwards to the roof so as to produce adequate pressure. I would avoid the use of bismuth and iodoform paste as this would irritate the nasal mucosa. Forty-eight hours later the morphine can be discontinued provided that the bleeding has ceased but further sedation with diazepam is helpful and then the patient is gradually mobilized out of bed.

One should not forget Trotter's method of controlling bleeding in an emergency. This consists in squeezing the tip (not the bridge) of the nose with a piece of cotton wool, biting on a cork to prevent swallowing, and sitting up not lying down. It is also important to look for causes of epistaxis of which sinusitis is often omitted. It is interesting to see how many patients admitted with epistaxis are in fact suffering from sinusitis and have no other symptoms at all. The bleeding ceases after adequate treatment.

Many operations have been advocated for persistent severe bleeding and these include ligating the internal maxillary artery by approaching the pterygopalatine fossa across the antrum by a Caldwell-Luc approach. This has been advocated by many otolaryngologists but I have never found it necessary once my patient has been treated adequately by complete rest, peace, and sedation.
There may be a vessel on the nasal mucosa near the front of the septum which can be cauterized. There is no reason why a chemical cautery should not be used, either silver nitrate on a stick or trichloroacetic acid, both of which give adequate local cauterization to the whole of Littler's area. They are not a diffuse smear as your article suggests and are just as effective as the electric cautery, which is rather oldfashioned and certainly frightens many young children. I would just add the point that it is often easier to cauterize a nose in a child using an aural rather than a nasal speculum; it is much more comfortable and the child is not frightened.-I am, etc.,

Liverpool

J. SiEgLER

SIR,-In your leading article on nosebleeding (9 March, p. 405) you advocate ine use of the postnasal pack where the bleeding oomes from far back in the cavity and is not controllable by anterior packing. While I agree that a posterior pack must be inserted, the bleeding point in such cases generally lies within one nasal cavity anterior to the postnasal space. It is therefore more logical to insert a pack rolled from 2 -inch $(5-\mathrm{cm})$ ribbon gauze to a diameter to fit the nose in question and medicated with bismuth and iodoform paste. To this roll is sewn a length of tape and this is drawn into the nose via the postnasal space, guided by a catheter passed through the nose. This converts the affected nostril into a closed cavity allowing a very firm anterior nasal pack to be placed against it. The two ends of the tape are tied together and strapped to the cheek. As you say, this is a hospital procedure requiring a general anaesthetic.-I am, etc.,

Boston, Lincs

J. E. A. KNOWLES

Streptokinase and Heparin in Treatment of Pulmonary Embolism

SIR,-In the controlled clinical trial of streptokinase and heparin in the treatment of pulmonary embolism reported by Dr. D. A. Tibbutt and others (2 March, p. 343) the solution used as a loading dose contained (1) $0.9 \%$ saline or $5 \%$ dextrose as the vehicle, (2) hydrocortisone $100 \mathrm{mg}$, and (3) streptokinase 500,000 units or heparin 5,000 units. The results of treatment in 30 patients entered in the trial appeared to demonstrate that the patients who received streptokinase showed a significantly greater evidence of thrombolysis on angiographic appearances.

As the authors admit, this was a very selected group because all except one patient had already survived more than six hours after the major episode of pulmonary embolism. However, I would maintain that the treatments in this trial were not comparable; there was a bias in favour of streptokinase. In an article published in the same issue (p. 383) Mrs. Patricia Brodlie and her colleagues state that heparin should not be mixed with hydrocontisone because they are incompatible. In addition, heparin should preferably not be mixed with $5 \%$ glucose, which is an acid solution and can reduce its potency. I would suggest, there- fore, that the study is biased in favour of streptokinase and is therefore not valid.-I am, etc.,

WILliam MacGowan

Department of Surgery,

Royal College of Surgeons in Ireland

Dublin

1 Drugs and Therapeutics Bulletin, 1970. 8, 55.

\section{Diet and Colonic Cancer}

SIR,-Your leading article (2 March, p. 339) discusses evidence for deoxycholic acid being one of the carcinogens concerned in cancer of the colon. In the original work on which this proposition is based ${ }^{1}$ large doses had to be used together with an adjuvant, which throws doubt on whether deoxycholic acid was the carcinogen responsible for the tumours which did oocasionally develop in the mice. The small intestine, liver, and biliary tree are daily in contact with deoxycholate in quantities and concentrations far greater than the oolon, ${ }^{2}$ yet cancer of these organs is much less common. The enterohepatic circulation is normally perfused by bile salts approximately $50 \%$ of which are dihydroxycholanic acids. ${ }^{3}{ }^{4}$ Indeed, a hepatic regulating mechanism exists in man for maintaining the proportion of dihydroxycholanic to trihydroxycholanic acids within narrow limits. ${ }^{3}$ Rabbit's bile contains deoxycholate as its principal bile salt. ${ }^{5}$ Deoxycholate probably is a marker of colonic bacterial activity under certain circumstances, and the amount in bile relative to other bile salts falls after colectomy ${ }^{6}$ and antibiotic therapy.

The relationship between diet, constipation, colonic bacterial metabolism, and colonic cancer may well prove a profitable line of research. The evidence so far that incriminates deoxycholate per se as a carcinogen is much too weak to quote in a review article.-I am, etc.,

THOMAS S. LOW-BEER

University Department of Medicine, Bristol Royal Infirmary,

1 Cook, J. W., Kennaway, E. L., and Kennaway, N. W., Nature, 1940, 145, 627.

2 Heaton. K. W., Gut, 1969, 10.857. Low-Beer, T. S., Pomare, E. W., and Mew Biology, 1972, 283, 215. J. S., Nature New Biology, 1972, 283, 215 . wi-senschaft, 1971, 10, 160.

5 Haslewood, G. Bile Salts. London, Methuen, 1967

Korris, J. S., Low-Beer, T. S., and Heaton, enterology. 1973, 8. 425 .

Hamilton, J. G., Archives of Biochemistry and Biophysics, 1963, 101, 7 .

\section{Continuous Diaphragm Sign of}

Pneumomediastinum

SIR,-Attention has been called to a newly recognised radiological finding which is stated to be present in a small number of cases of pneumomediastinum. On a normal frontal chest film visualization of the central part of the diaphram is lost owing to the apposition of the heart. Air interposed between the heart and the diaphragm results in a gas-tissue interface over this part of the diaphragm as well as that underlying the lung, so that the superior aspect becomes visible right across the thorax. Levin ${ }^{1} \mathrm{re}$ ported three cases and called this the "continuous diaphragm sign." 